\title{
Our Clinical Experience of Self-Expanding Metal Stent for Malignant Central Airway Obstruction
}

\author{
Akash Verma $^{\text {a, c }}$, Chee Kiang Phua ${ }^{\mathrm{a}}$, Qiu Mei Wu ${ }^{\mathrm{a}}$, Wen Yuan Simª ${ }^{\mathrm{a}}$ Audrey Wee Chuan Rui ${ }^{\mathrm{a}}$, \\ Soon Keng Goh ${ }^{\mathrm{a}}$, Benjamin Ho ${ }^{\mathrm{a}}$, Ai Ching Kor ${ }^{\mathrm{a}}$, Andrew S. Y. Wong ${ }^{\mathrm{b}}$, Albert Y. H. Limª, \\ Dessmon Y. H. Tai ${ }^{\text {a }}$ John Abisheganaden ${ }^{\mathrm{a}}$
}

\begin{abstract}
Background: We studied the safety, effectiveness, and limitations of airway stenting using self-expanding metal stent (SEMS) in patients with malignant central airway obstruction (CAO).

Methods: A retrospective review of records of patients undergoing SEMS placement for malignant CAO during year 2013 - 2014 was done.

Results: Sixteen patients (11 males and five females) underwent SEMS placement for malignant CAO. Median (range) age was 66 (54 - 78) years. No perioperative or immediate postoperative complications were seen except acute myocardial infarction (AMI) in one patient. Three patients were transferred to intensive care unit (ICU) for closer monitoring after the procedure and were discharged the next day. All four patients with lung atelectasis on presentation experienced complete re-expansion of the lung post-stenting. The dyspnea was substantially relieved in $14(87.5 \%)$ patients. Two of the three patients who had been intubated were weaned off from the ventilator following stent insertion. Stent patency was maintained until death in all patients except one. Median survival from the date of diagnosis and the date of stent placement in lung cancer, esophageal cancer, and thyroid cancer were $140(21$ - 564) and 85 (15 - 361), 288 (80 - 419) and 61 (60 - 171), and $129(71$ - 187) and 67 (16 - 118) days, respectively. This survival was similar to reported expected survival associated with the underlying malignancy. During follow-up, granulation tissue $(n=1)$, mucostasis $(n=1)$, and tumor ingrowth $(\mathrm{n}=2)$ were the most frequently encountered complications.
\end{abstract}

Conclusion: SEMSs are safe and effective in reversing respiratory failure caused by malignant $\mathrm{CAO}$, averting premature death, allowing application of cancer targeted therapy, and restoring impending shortened survival to expected life expectancy associated with the underlying malignancy.

Manuscript accepted for publication November 09, 2016

aDepartment of Respiratory and Critical Care Medicine, Tan Tock Seng Hospital, Singapore 308433, Singapore

bDepartment of General Surgery, Changi General Hospital, Singapore 529889, Singapore

${ }^{\mathrm{c} C o r r e s p o n d i n g ~ A u t h o r: ~ A k a s h ~ V e r m a, ~ D e p a r t m e n t ~ o f ~ R e s p i r a t o r y ~ a n d ~ C r i t i c a l ~}$ Care Medicine, Tan Tock Seng Hospital, 11 Jalan Tan Tock Seng, Singapore 308433, Singapore. Email: Akash_Verma@ttsh.com.sg

doi: https://doi.org/10.14740/jocmr2811w
Keywords: Lung cancer; Bronchoscopy; Central airway obstruction; Stent

\section{Introduction}

Central airway obstruction (CAO) is an uncommon but potentially life-threatening condition that can be due to a number of malignant diseases. For example, airway obstruction complicates approximately $20-30 \%$ of patients with lung cancer [1]. This can result from either the direct endobronchial extension of a tumor or extrinsic compression from parenchymal lung mass, lymph-node, and esophageal or thyroid cancer [2]. Clinically, malignant CAO presents with dyspnea, stridor, or cough. Radiologically, it can present with lobar or complete lung atelectasis. Physiologically, it can manifest as air flow obstruction on spirometry with characteristic changes in flow volume loop (FVL) such as blunting of the expiratory and inspiratory limb of the FVL in case of fixed airway obstruction, or biphasic FVL in case of unilateral mainstem bronchus obstruction $[2,3]$. Interventional bronchoscopy with airway stenting by virtue of re-establishment of the patency of the airway provides immediate relief of dyspnea, resolution of radiological and physiological changes, improves functional status, and confers stabilization of clinical condition to allow administration of definitive therapies targeted at cancer [2]. Other interventional bronchoscopic techniques used for the recanalization of the malignant $\mathrm{CAO}$ are the laser resection, coring of the tumor with the rigid tube, and brachytherapy [2]. In addition to palliation, survival benefit has also been described if performed early [4]. In CAO from extrinsic compression, two types of stents are used for recanalization. Silicone stents are preferred for benign diseases, whereas metal stents can be used for malignant $\mathrm{CAO}$ [5]. We describe our clinical experience in using self-expanding metal stent (SEMS) for malignant CAO.

\section{Materials and Methods}

We performed a retrospective analysis of 16 patients treated with SEMS for malignant CAO from January 1, 2014 to November 30,2015 . We collected data on oxygenation, radio- 

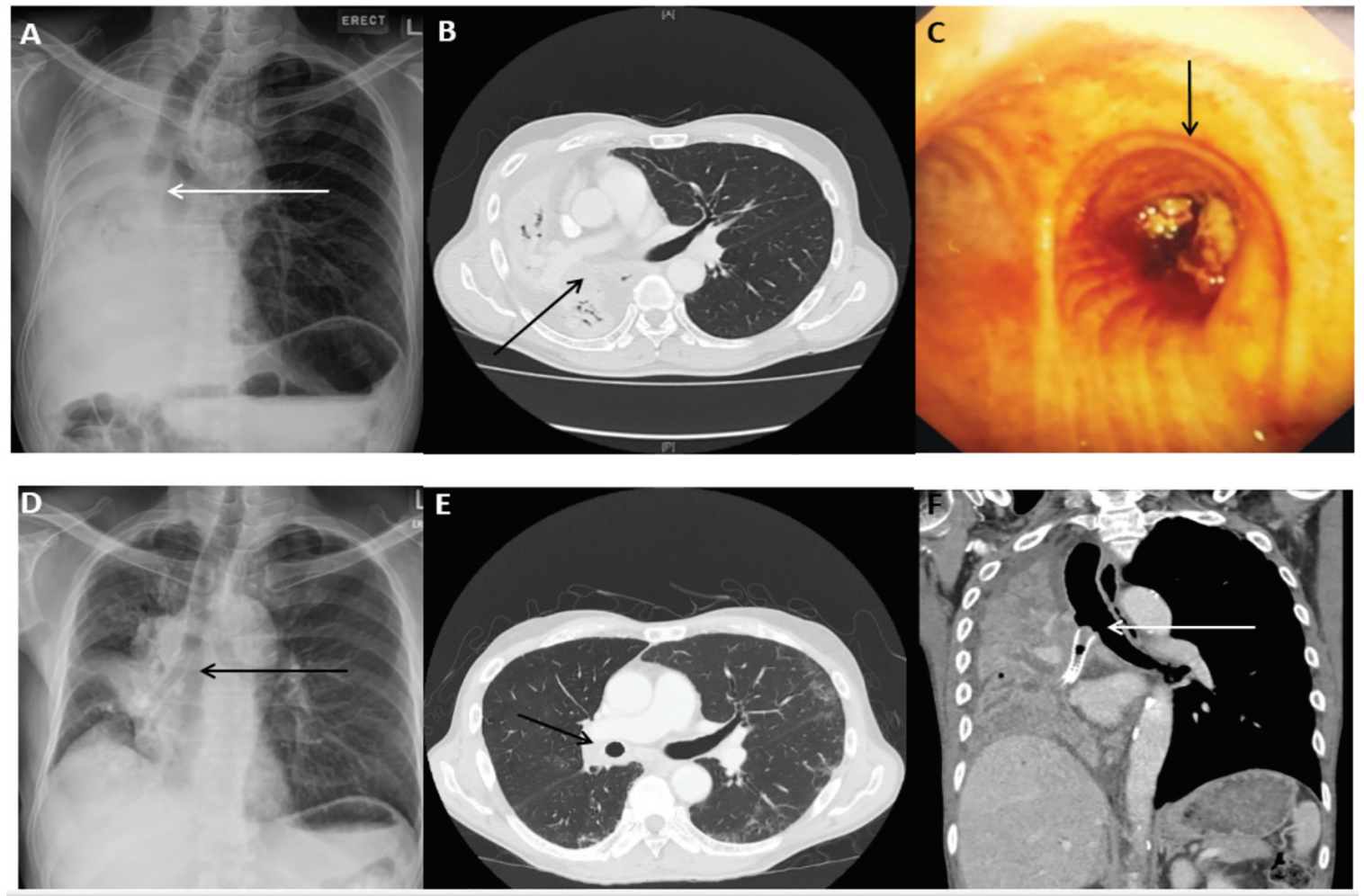

Figure 1. Representative case of malignant central airway obstruction in a 60-year-old male with squamous cell carcinoma. (A) Complete right lung collapse on the radiograph at the time of initial presentation with the cut off of the right main bronchus (arrow). (B) CT scan of the chest (axial view) showing collapsed right lung. (C) Visible endobronchial tumor obstructing the right main bronchus on bronchoscopy. (D) Re-expansion of the right lung following the SEMS placement in the right main bronchus and bronchus intermedius (arrow). (E) Post-stent placement CT scan of the chest (axial view) showing re-expansion of the right lung and stent in-situ (arrow). (F) CT scan of the chest 1 year later showing tumor ingrowth and recurrence of lung collapse.

graphic changes, bronchoscopic appearance, type of intervention, complications of intervention, safety, and effectiveness of SEMS. Approval from our institutional review board was obtained.

Flexible and rigid bronchoscopies were performed using standard techniques [1]. Nd-YAG laser resection (Laser sonic Model 8000; Heraeus Surgical, Milpitas, CA) was performed using 15 - to $30-\mathrm{W}$ pulses and pulse duration of $0.5-1.0 \mathrm{~s}$. Coring of the tumor was carried out using the rigid tube where necessary. Flexible bronchoscopy through the rigid tube was employed as necessary to help clear the airways of secretions and blood. In cases with extrinsic compression from malignant obstruction, Boston Scientific Ultraflex SEMSs were deployed using the Ultraflex ${ }^{\mathrm{TM}}$ Tracheobronchial Stent System via standard technique. Only covered Ultraflex self-expanding stents were used. Covered SEMSs are coated with a silicone sheath except $0.5 \mathrm{~cm}$ of their proximal and distal end.

\section{Definitions}

CAO was defined as the obstruction of the trachea and mainstem bronchi. Respiratory failure was defined as stridor, need for supplemental oxygen, or need for mechanical ventilation. Survival was calculated from date of diagnosis-to-date of death or November 30, 2015.

\section{Data analysis}

We used software (SPSS, version 17; SPSS, Chicago, IL) for all statistical analyses. The results were compared using a Wilcoxon two-sample test or Fisher's exact test. P values were two-sided and considered indicative of a significant difference if less than 0.05 .

\section{Results}

Sixteen patients (11 males and five females) underwent stenting in 1 year. Median (range) age was 66 (54 - 78) years. Eighteen stents were placed in 16 patients, with one patient needing two stents in both bronchi and one needing two adjacent stents in right main bronchus and bronchus intermedius (Fig. 1). Nine (56.2\%) patients had primary lung cancer, five $(31.2 \%)$ had esophageal cancer, and two $(12.5 \%)$ had thyroid cancer. Three patients received mechanical ventilation before the procedure (Table 1). Two patients underwent concurrent laser prior to stent placement. Four patients had lobar or complete lung atelectasis on presentation. Procedures were done 


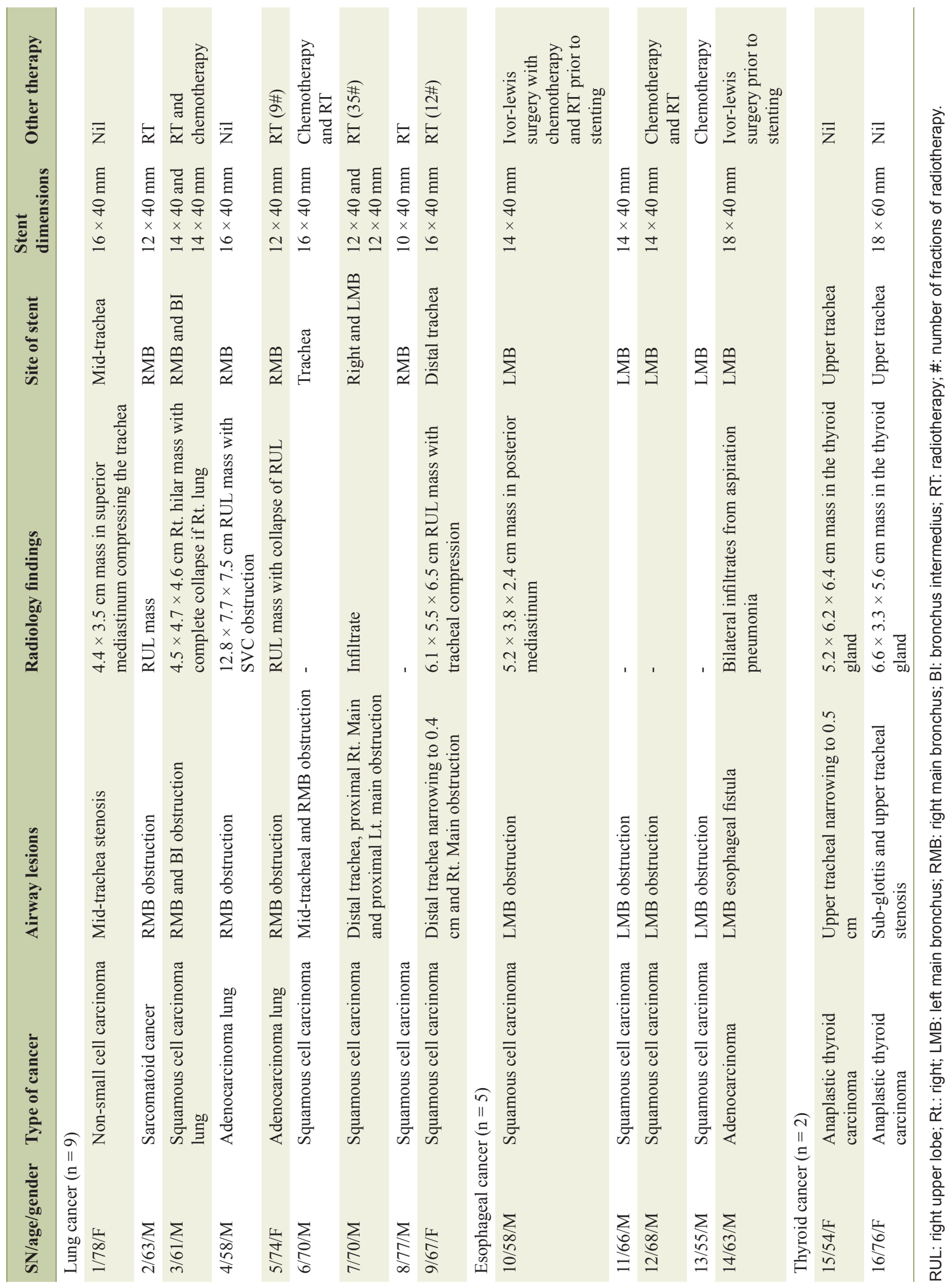


Table 2. Survival of Patients Having Malignant COA and Treated With SEMS in Comparison to the Expected Survival Associated With the Underlying Malignancy $(n=16)$

\begin{tabular}{|c|c|c|c|c|c|}
\hline & $\begin{array}{l}\text { Respiratory } \\
\text { failure }\end{array}$ & $\begin{array}{l}\text { Diagnosis- } \\
\text { to-stenting } \\
\text { time (days) }\end{array}$ & $\begin{array}{l}\text { Diagnosis-to-death time or } \\
\text { last follow-up time (actual } \\
\text { life expectancy in days) }\end{array}$ & $\begin{array}{l}\text { Stenting-to- } \\
\text { death or last } \\
\text { follow-up (days) }\end{array}$ & $\begin{array}{l}\text { Expected life } \\
\text { expectancy }\end{array}$ \\
\hline Non-small cell lung cancer & Yes & 14 & 74 & 60 & \\
\hline Sarcomatoid cancer & Yes & 40 & 220 & 180 & \\
\hline Squamous cell carcinoma lung & Yes & 1 & 362 & 361 & \\
\hline Adenocarcinoma lung & Yes & 39 & 54 & 15 & \\
\hline Adenocarcinoma lung & No* & 11 & 347 & 336 & \\
\hline Squamous cell carcinoma & No & 516 & 564 & 48 (alive) & \\
\hline Squamous cell carcinoma & Yes & -12 & 140 & 152 (alive) & \\
\hline Squamous cell carcinoma & No & 4 & 89 & 85 (alive) & \\
\hline Squamous cell carcinoma & Yes & 6 & 21 & 15 (alive) & \\
\hline $\begin{array}{l}\text { Lung cancer }(n=9), \text { median } \\
\text { (range) }\end{array}$ & & $11(-12-516)$ & $140(21-564)$ & $85(15-361)$ & $\begin{array}{l}10(8-12) \\
\text { months }[13]\end{array}$ \\
\hline Squamous cell carcinoma & Yes & 323 & 419 & 96 & \\
\hline Squamous cell carcinoma & No & 299 & 360 & 61 & \\
\hline Squamous cell carcinoma & Yes & 117 & 288 & 171 & \\
\hline Squamous cell carcinoma & No & 20 & 8 & 60 & \\
\hline Adenocarcinoma & Yes & 56 & 117 & 61 & \\
\hline $\begin{array}{l}\text { Esophageal cancer }(\mathrm{n}=5) \text {, median } \\
\text { (range) }\end{array}$ & & $117(20-323)$ & $288(80-419)$ & $61(60-171)$ & $\begin{array}{l}9(8-10) \\
\text { months }[15-17]\end{array}$ \\
\hline Anaplastic thyroid carcinoma & Yes & 55 & 71 & 16 & \\
\hline Anaplastic thyroid carcinoma & Yes & 69 & 187 & 118 & \\
\hline $\begin{array}{l}\text { Anaplastic thyroid cancer }(\mathrm{n}=2) \text {, } \\
\text { median (range) }\end{array}$ & & $62(55-69)$ & $129(71-187)$ & $67(16-118)$ & $\begin{array}{l}3.8(3-4.6) \\
\text { months }[14]\end{array}$ \\
\hline All $(n=16)$ & & $39.5(-12-516)$ & $163.5(21-564)$ & $73(15-361)$ & \\
\hline
\end{tabular}

*Patients without respiratory failure in the lung carcinoma group underwent stent placement to prevent worsening of the airway obstruction secondary to radiation therapy. Patients without respiratory failure in the esophageal carcinoma group underwent stent placement prior to esophageal stenting to prevent airway compromise from esophageal stenting.

under general anesthesia in operation room via the rigid bronchoscopy. No perioperative or immediate postoperative complications were seen except acute myocardial infarction (AMI) on day after the procedure in one patient. Three patients were transferred to intensive care unit (ICU) for closer monitoring after the procedure and were discharged the next day. All four patients with lung atelectasis on presentation experienced complete re-expansion of the lung post-stenting. The dyspnea was substantially relieved in 14 patients $(87.5 \%)$. All three patients who were intubated prior to intervention were weaned off from the ventilator following stent insertion.

During follow-up, granulation tissue $(n=1)$, mucostasis $(n=1)$, and tumor ingrowth $(n=2)$ were the most frequently encountered complications. Median survival from the date of diagnosis and the date of stent placement in from lung cancer, esophageal cancer, and thyroid cancer were $140(21$ - 564) and 85 (15 - 361), $288(80$ - 419) and 61 (60 - 171), and 129 (71 - 187) and 67 (16 - 118) days, respectively. This survival was similar to expected survival based on the life expectancy of the underlying malignancy (Table 2) [6-10].

\section{Discussion}

This study illustrates that SEMSs are safe and effective for managing malignant $\mathrm{CAO}$. They provide prompt reversal of respiratory failure and re-expansion of the collapsed lung. By reversing respiratory failure, they avert premature death and allow cancer targeted therapy to be undertaken. This restores the length of survival to the expected life expectancy associated with the primary cancer.

CAO develops secondary to endoluminal disease, external compression by a mediastinal or hilar tumor, bulky lymphadenopathy, or a combination of endoluminal and extrinsic disease [11]. There are a variety of treatment options that can restore airway patency in this group of patients [12-15]. Stents are employed when extrinsic compression is the dominating cause of the CAO. However, generally, airway stenting is 
Table 3. Complications of Stent Placement in Malignant Central Airway Obstruction

\begin{tabular}{llllll} 
& $\begin{array}{l}\text { McGrath et al [19] } \\
(\mathbf{n = 6 8 )}\end{array}$ & $\begin{array}{l}\text { Saad et al [20] } \\
(\mathbf{n = 8 2})\end{array}$ & $\begin{array}{l}\text { Cavaliere et al [2] } \\
(\mathbf{n = 3 0 6})\end{array}$ & $\begin{array}{l}\text { Breitenbucher et al [21] } \\
(\mathbf{n = 6 0 )}\end{array}$ & $\begin{array}{l}\text { Current study } \\
(\mathbf{n}=\mathbf{1 6})\end{array}$ \\
\hline Type of stent & Ultraflex SEMS & Ultraflex SEMS & Silicone stents & Ultraflex SEMS & Covered Ultraflex SEMS \\
Covered/uncovered & Uncovered (94\%) & Uncovered $(66 \%)$ & Not applicable & Uncovered $(18.3 \%)$ & Uncovered $(0)$ \\
Migration & $4(5.8 \%)$ & $4.7 \%$ & $18(6 \%)$ & $5 \%$ & 0 \\
Granulation tissue & $3(4.4 \%)$ & $14.6 \%$ & $3(0.9 \%)$ & $5 \%$ & $1(6.2 \%)$ \\
Mucostasis & Not reported & Not reported & $3(0.9 \%)$ & $8 \%$ & $1(6.2 \%)$ \\
Tumor ingrowth & $1(1.4 \%)$ & Not reported & Not reported & $5 \%$ & $2(12.5 \%)$ \\
Pneumonia & $2(2.9 \%)$ & $15.9 \%$ & $5(1.6 \%)$ & $10 \%$ & 0 \\
\hline
\end{tabular}

combined with some form of endoscopic tumor resection to achieve patency of the airway.

It is known that survival of patients with untreated malignant $\mathrm{CAO}$ is very poor and ranges from 1 to 2 months [16, 17]. Life expectancy in untreated advanced lung cancer is $4-5$ months [6]. Platinum-based chemotherapy improves survival in this group to $8-12$ months [6]. Similarly life expectancies in advanced esophageal carcinoma and anaplastic thyroid carcinoma are $9(8-10)$ and $3.8(3-4.6)$ months, respectively [710]. In this context, despite having $\mathrm{CAO}$, patients in our cohort lived to the level of the expected life expectancy associated with the underlying malignancy. The described and perceived benefits of the stenting are mainly relief of dyspnea, improved functional status, and better quality of life [18]. However, it is noteworthy that even though stenting does not increase survival per se, it supports survival by preventing premature death from respiratory failure, post-obstructive pneumonitis, and sepsis. It is also shown that patients having advanced lung cancer with locally treated malignant $\mathrm{CAO}$ in combination with chemotherapy live as long as their counterparts without CAO [18].

The American College of Chest Physicians (ACCP) has published an advisory against using metal stents in benign airway obstruction. Silicone stents are preferable in such diseases due to their ease of removal and re-introduction [5]. Some centers prefer silicone stents even for malignant CAO. However, limited life expectancy of patients with malignant $\mathrm{CAO}$ obviates the need for removal of the stent upon resolution of the stenosis. We found SEMS effective in restoring and maintaining the airway patency and at the same time easy to introduce and safe with no peri-procedural complications or mortality. Relative ease of their insertion carries the potential to broaden the proportion of patients they can be offered to.

We found that lung cancer patient with CAO presents at the time of initial diagnosis, whereas patients with thyroid carcinoma and esophageal carcinoma develop CAO significantly later in the course of their disease. In our cohort, CAO developed at the median interval of 3.9 months after the diagnosis of esophageal cancer, and 2 months after the diagnosis of thyroid cancer. Since early intervention is preferable, this information can allow physicians to determine the timing of follow-up in outpatient clinic and time for repeating the imaging study to look for the development of $\mathrm{CAO}$ with the intent to identify and intervene early before the development of significant air- way compromise.

Regarding complications of the SEMS, mucostasis, granulation tissue formation, and tumor ingrowth at the edges of the stent were seen, out of which tumor ingrowth was the most frequent and detrimental complication as it compromised the patency of the airway irreversibly. No patient experienced stent migration (the most significant and frequent complication of the silicone stents) in our cohort even after the resolution of $\mathrm{CAO}$ from radiotherapy and chemotherapy. Complications associated with SEMSs are well documented. In a retrospective analysis of 68 patients undergoing Ultraflex SEMSs insertion for malignant tracheobronchial stenosis, most of which were uncovered, complications included hemorrhage originating in the area of the stent placement during the insertion itself (one patient), mild hemoptysis (five patients), stent migration (four patients), severe granulation tissue (three patients), pneumonia (two patients), odynophagia, respiratory failure, stent occlusion, and deployment failure (one patient in each case). There were no episodes of fistula formation, lobe collapse, pneumothorax or sudden death [19]. In another study of 82 patients, Saad et al reported the occurrence of infection in $15.9 \%$, obstructive granulomas in $14.6 \%$, and migration in $4.7 \%$ [20]. Most of the patients received an uncovered stent in this cohort too. In a study by Breitenbucher et al in patients with malignant diseases, they observed a complication of mucus plugging in $8 \%$ of the cases, as well as stent migration, the formation of granulation tissue and the re-stenosis of the tumor in $5 \%$ of cases, each [21]. The lower incidence of stent migration in our cohort is consistent with the existing literature (Table 3) [2, 1921]. In comparison with silicone stents, Ultraflex stents have a lower rate of migration due to their epithelialization, but with a higher rate of granulation tissue formation [21]. Stents were patent in most patients until the time of death as evidenced by computed tomography (CT) or bronchoscopy done close to the time of death indicating that prognosis of underlying cancer was the determinant of length of survival rather than stent failure.

In conclusion, SEMSs not only offer minimally invasive palliative therapy for patients suffocating from un-resectable malignant $\mathrm{CAO}$ with low complication risk, but also preserve survival by averting premature death from respiratory failure, and conferring clinical stability to allow cancer targeted therapy to take place. Tumor ingrowth at the uncovered edges of the stent is the most significant and irreversible complication. 
Completely covered SEMSs may help to overcome this complication.

\section{Acknowledgments}

Authors would like to thank Ms. Ivy Yu Ling Ling for her valuable contribution in editing the tables and administrative work.

\section{Conflicts of Interest}

AV, CKP, QMW, WYS, AWCR, SKG, BH, ACK, ASYW, AL, DYHT, and JA have no competing financial interests to disclose.

\section{References}

1. Ernst A, Feller-Kopman D, Becker HD, Mehta AC. Central airway obstruction. Am J Respir Crit Care Med. 2004;169(12):1278-1297.

2. Cavaliere S, Venuta F, Foccoli P, Toninelli C, La Face B. Endoscopic treatment of malignant airway obstructions in 2,008 patients. Chest. 1996;110(6):1536-1542.

3. Marchese R, Poidomani G, Paglino G, Crimi C, Lo Nigro C, Argano V. Fully covered self-expandable metal stent in tracheobronchial disorders: clinical experience. Respiration. 2015;89(1):49-56.

4. Razi SS, Lebovics RS, Schwartz G, Sancheti M, Belsley S, Connery CP, Bhora FY. Timely airway stenting improves survival in patients with malignant central airway obstruction. Ann Thorac Surg. 2010;90(4):1088-1093.

5. Lund ME, Force S. Airway stenting for patients with benign airway disease and the Food and Drug Administration advisory: a call for restraint. Chest. 2007;132(4):11071108.

6. Alberts Michael W. American College of Chest Physicians. Pulmonary Board Review. 2009;39-62.

7. Lim SM, Shin SJ, Chung WY, Park CS, Nam KH, Kang SW, Keum KC, et al. Treatment outcome of patients with anaplastic thyroid cancer: a single center experience. Yonsei Med J. 2012;53(2):352-357.

8. Polee MB, Hop WC, Kok TC, Eskens FA, van der Burg ME, Splinter TA, Siersema PD, et al. Prognostic factors for survival in patients with advanced oesophageal cancer treated with cisplatin-based combination chemotherapy. Br J Cancer. 2003;89(11):2045-2050.

9. Millikan KW, Silverstein J, Hart V, Blair K, Bines S,
Roberts J, Doolas A. A 15-year review of esophagectomy for carcinoma of the esophagus and cardia. Arch Surg. 1995;130(6):617-624.

10. Cancer Research UK. Statistics and outlook for oesophageal cancer. http://www.cancerresearchuk.org/aboutcancer/type/oesophageal-cancer/treatment/statistics-andoutlook-for-oesophageal-cancer.

11. Stohr S, Bolliger CT. Stents in the management of malignant airway obstruction. Monaldi Arch Chest Dis. 1999;54(3):264-268.

12. Chin CS, Litle V, Yun J, Weiser T, Swanson SJ. Airway stents. Ann Thorac Surg. 2008;85(2):S792-796.

13. Bolliger CT, Mathur PN, Beamis JF, Becker HD, Cavaliere S, Colt H, Diaz-Jimenez JP, et al. ERS/ATS statement on interventional pulmonology. European Respiratory Society/American Thoracic Society. Eur Respir J. 2002;19(2):356-373.

14. Ernst A, Silvestri GA, Johnstone D. Interventional pulmonary procedures: Guidelines from the American College of Chest Physicians. Chest. 2003;123(5):1693-1717.

15. Bolliger CT, Sutedja TG, Strausz J, Freitag L. Therapeutic bronchoscopy with immediate effect: laser, electrocautery, argon plasma coagulation and stents. Eur Respir J. 2006;27(6):1258-1271.

16. Walser EM, Robinson B, Raza SA, Ozkan OS, Ustuner E, Zwischenberger J. Clinical outcomes with airway stents for proximal versus distal malignant tracheobronchial obstructions. J Vasc Interv Radiol. 2004;15(5):471-477.

17. Macha HN, Becker KO, Kemmer HP. Pattern of failure and survival in endobronchial laser resection. A matched pair study. Chest. 1994;105(6):1668-1672.

18. Chhajed PN, Baty F, Pless M, Somandin S, Tamm M, Brutsche $\mathrm{MH}$. Outcome of treated advanced non-small cell lung cancer with and without central airway obstruction. Chest. 2006;130(6):1803-1807.

19. McGrath EE, Warriner D, Anderson P. The insertion of self expanding metal stents with flexible bronchoscopy under sedation for malignant tracheobronchial stenosis: a single-center retrospective analysis. Arch Bronconeumol. 2012;48(2):43-48.

20. Saad CP, Murthy S, Krizmanich G, Mehta AC. Self-expandable metallic airway stents and flexible bronchoscopy: long-term outcomes analysis. Chest. 2003;124(5):19931999.

21. Breitenbucher A, Chhajed PN, Brutsche MH, Mordasini C, Schilter D, Tamm M. Long-term follow-up and survival after Ultraflex stent insertion in the management of complex malignant airway stenoses. Respiration. 2008;75(4):443-449. 